Article

\title{
An Internet of Things (IoT) Acceptance Model. Assessing Consumer's Behavior toward IoT Products and Applications
}

\author{
Maria Tsourela * and Dafni-Maria Nerantzaki \\ Department of Business Administration, International Hellenic University, 62100 Serres, Greece; \\ nerdafni@hotmail.com \\ * Correspondence: mt@ihu.gr; Tel.: +30-23210-49340
}

Received: 2 October 2020; Accepted: 22 October 2020; Published: 3 November 2020

check for updates

\begin{abstract}
A common managerial and theoretical concern is to know how individuals perceive Internet of Things (IoT) products and applications and how to accelerate adoption of them. The purpose of the current study is to answer, "What are the factors that define behavioral intention to adopt IoT products and applications among individuals?" An IoT adoption model was developed and tested, incorporating pull factors from two different information impact sources: technical and psychological. This study employs statistical structural equation modeling (SEM) in order to examine the conceptual IoT acceptance model. It is demonstrated that facilitated appropriation, perceived usefulness and perceived ease of use, as mediators, significantly influence consumers' attitude and behavioral intention towards IoT products and applications. User character, cyber resilience, cognitive instrumentals, social influence and trust, all with different significance rates, exhibited an indirect effect, through the three mediators. The IoT acceptance model (IoTAM) upgrades current knowledge on consumers' behavioral intention and equips practitioners with the knowledge needed to create successful integrated marketing tactics and communication strategies. It provides a solid base for examining multirooted models for the acceptance of newly formed technologies, as it bridges the discontinuity in migrating from information and communication technologies (ICTs) to IoT adoption studies, causing distortions to societies' abilities to make informed decisions about IoT adoption and use.
\end{abstract}

Keywords: Internet of Things (IoT); IoT acceptance model (IoTAM); consumer behavior; behavioral intention; technology adoption

\section{Introduction}

Internet of Things, or IoT, refers to the billions of physical objects around the world, wirelessly connected to the internet and each other, collecting and sharing data. Cheap processors and wireless networks can integrate anything into the IoT. Such a procedure adds digital intelligence to devices, by allowing them to communicate by themselves. The idea of adding sensor and intelligence to basic objects was discussed throughout the 1980s and 1990s, but apart from some early projects, such as an internet-connected vending machine, progress was slow, simply because the technology was not ready. The term Internet of Things (IoT) was coined in 1999 by Ashton [1], a British technology pioneer, during a presentation he made at Procter \& Gamble (P\&G). "The IoT integrates the interconnectedness of human culture - our 'things' - with the interconnectedness of our digital information system - 'the internet.' That's the IoT," Ashton [1]. The IoT aims to extend the benefits of the regular internet-constant connectivity, remote control ability, data sharing, and so on-to goods in the physical world [2]. Its powerhouse is efficiency and innovation, enabling connectivity for everyone, everything and everywhere. 
The IoT is the hot trend in the tech and business world. McLellan [3] states that, "IoT is a fast-growing constellation of Internet-connected sensors attached to a wide variety of things". There are numerous real-world applications of IoT such as smart homes, wearable devices, smart healthcare, smart buildings, smart city, smart farming, smart appliances and so on, ranging from consumer IoT and enterprise IoT to manufacturing and industrial IoT (IIoT). IoT applications span numerous verticals, including automotive, telecommunications, energy and more.

Some widely used technology acceptance theories may not be eligible or applicable for exploring individuals' adoption of IoT applications. After the technology acceptance model (TAM) [4] and its extensions were heavily criticized [5-7], more antecedents were incorporated leading to the creation of Unified Theory of Acceptance and Use of Technology (UTAUT) and later to UTAUT2 models [8].

Several studies have investigated the technical issues of implementing IoT technology [9]. Hancke, Markantonakis and Mayes [10] and Medaglia and Serbanati [11] identified the security and privacy issues as the major challenges for user-oriented IoT applications. Mendez and Papapanagiotou [12] explored IoT security. Uckelmann, Harrison and Michahelles [13] explained the architecture of IoT. Guinard, Trifa, Mattern and Wilde [14] outlined IoT best practices based on the web technologies and recommended prototypes using the web principles. Hyun Gi Hong [15] found that factors, such as technical issues, personal characters, environmental factors, and cost factor affect the users' adoption of IoT products. The original IoT aimed to increase supply chain efficiencies for organizations [16], but more recently the potentials of IoT applications in social networking [16], smart cities [17] and m-health [18] have been explored. Gao, Li and Luo [19] showed that all factors from technology acceptance, health behavior, and privacy context perspectives would significantly affect consumers' decision to adopt wearable technology in healthcare.

Potential discrepancies between IoT and the adoption process of other information technologies must be factored. It is unlikely that even complicated technology adoption models will fail to investigate IoT adoption [8]. Though IoT's overarching aim is to make an individual's life easier and simpleminded, there may be other objections that could decelerate or even hinder its adoption process. Much prior research has focused on the design and usage of IoT technologies from the point of view of the organization or industry [20], while little attention has been devoted to understanding the acceptance of IoT technologies from the perspective of individual consumers [21]. According to Evanschitzky, Iyer, Pillai, Kenning and Schütte [22], IoT technology needs further research in order to understand the factors that determine its acceptance.

The common managerial and theoretical concerns are to know how individuals perceive IoT products and applications and how to accelerate adoption of them. It is an overriding requirement to try to explain the behavioral intention of individuals towards IoT without neglecting either technical or psychological attribute data. The main research question is "what factors define the behavioral intention to adopt IoT products and applications among individuals?" Thus, the research's goal is to develop and test a model explaining the attitude and behavioral intention towards IoT products and applications by individuals, incorporating pull factors from two different information impact sources: technical and psychological.

Previous research has focused mainly on the driving factors behind IoT systems from the perspective of the enterprise [23]. This research, however, differs because it focuses on IoT usage from the consumers' perspective. Additionally, this study explores the factors that affect perceived usefulness, perceived ease of use and attitude in the context of IoT systems. Even though the previous studies have enriched our knowledge about factors influencing consumers' intention to use information systems, they have not thoroughly examined the IoT systems.

The overall significance of this new IoT acceptance model (IoTAM) can create the prospect of instilling awareness for IoT dynamics. According to Prayoga and Abraham [24], IoT acceptance is based on techno-psychological points of view and acceptance must be explained in terms of its affective, cognitive, behavioral, and technological elements. The findings will be used to advance knowledge in this newly introduced technology, by providing a collection of techno-psychological factors that define 
IoT acceptance and help create strategies for management and other stakeholders who are interested in the successful implementation of IoT.

\section{Conceptual Model and Hypothesis}

In conducting this study, an effort was made to understand what consumer beliefs explain attitude and behavioral intention towards IoT products and applications. It was felt that variables other than the ones proposed from TAM and other technology acceptance models could be equally or more important. The new IoTAM for predicting behavioral intention towards IoT will reveal the determinants that influence IoT products and applications adoption.

\subsection{Behavioral Intention}

In prominent technology acceptance and use models, the relationships between all individual or environmental antecedents and actual use are mediated by behavioral intention, defined as the strength of an individual's desire to perform a behavior, which intends to capture "acceptance-like" processes $[25,26]$.

In the realm of TAM, intention, or behavioral intention (BI), is the main indicator of acceptance- the higher the BI, the higher the likeliness to accept the technology [27,28]. Understanding individuals' intentions and the reasons that they are willing to use product or service is crucial for marketers and managers, since individuals' attitudes are connected with their perceptions [29]. Hence, it is concluded, in the context of IoT, in the form of the following hypothesis.

Hypothesis 1 (H1). Attitude toward IoT products and applications usage is positively associated with individuals' behavioral intention to use them.

\subsection{Attitude}

Previous studies confirm the impact of perceived usefulness (PU) and perceived ease of use (PEOU) on both attitude and behavioral intention to use a product [30]. One of the main reasons for the slow pace in acceptance of IoT technology applications could be a failure in communicating a clear benefit to potential users. In the context of TAM, this view is reflected by the PU construct. Accordingly, the PU of IoT products and applications is likely to be high. Relating to IoT technologies, Gao and Bai [31] validated two factors of the original TAM — usefulness and ease of use-as the determinants of user intentions regarding IoT technologies.

Judged from this standpoint, the following hypotheses are recommended:

Hypothesis 2 (H2). Perceived usefulness is positively associated with individuals' attitude towards IoT products and applications.

Hypothesis 3 (H3). Perceived ease of use is positively associated with individuals' attitude towards IoT products and applications.

\subsection{Facilitated Appropriation}

In many cases, technology serves another purpose than the one originally intended. Likewise, in the IoT spectrum, products and applications can be appropriated in many ways. Appropriation is the way in which technologies are adopted, adapted, and incorporated into working practice. The next element integrated in the proposed model is the concept of facilitated appropriation, acting as factor of influence for PU.

Facilitated appropriation (FA) can be seen as a more comprehensive and systematic appropriation. While engaging in facilitated appropriation, individuals are inspired to see and engage with additional features on a device, exclusively dealing with their problems or other personal purposes $[27,28]$. In this 
research, it is proposed that if individuals feel they are facilitated to appropriate IoT products and applications, they would be more likely to view the technology as useful.

Long-term orientation and flexibility. Facilitated appropriation will be examined by means of long-term orientation and flexibility, which are the exogenous variables affecting facilitated appropriation. Long-term orientation (LTO) is a salient aspect of national culture values and as such influences consumers' decision-making processes [32]. Prayoga and Abraham [27,28] found that among cultural values, only LTO predicts user's tendency to engage in facilitated appropriation. Based on these arguments, the following hypothesis is recommended.

Hypothesis 4 (H4). A consumers' facilitated appropriation can predict his/her perceived usefulness towards IoT products and applications.

\subsection{Perceived Usefulness}

PEOU is expected to influence attitude either directly (H3) or indirectly, through its effect on PU. According to Davis [4] and Venkatesh and Davis [33], the relationship between PEOU and PU is explained in the following manner, if an individual perceives use of any technological product/system as easy to use and free of effort, he or she perceives that product/system is more useful. Revels et al. [26] found that PEOU is a strong predictor of PU in the context of mobile commerce. With these considerations, the following hypothesis is recommended:

Hypothesis 5 (H5). There is a positive relationship between PEOU and PU in the context of IoT.

\subsection{Trust}

As IoT products and applications consistently require access to one's data, they must be built under a "zero trust" model. Trust is evidenced as a good predictor of usefulness, ease of use, behavioral intention, and attitude [34]. It is the gateway to technology acceptance, especially in the IoT arena, where any of your information is at potential risk [27,28].

The connections between trust and TAM are widely discussed in literature, in that the relationships between PU, PEOU, and trust are hypothesized in many online-based businesses settings [35]. Trust is recognized to have positive effect on $\mathrm{PU}$, since trust allows consumers to become vulnerable to the e-vendor, ensuring they gain the expected useful interaction and service [35]. Accordingly, this study recommends the following hypotheses:

Hypothesis 6 (H6). Trust will positively influence perceived usefulness related to IoT products and applications.

Hypothesis 7 (H7). Trust will positively influence perceived ease of use related to IoT products and applications.

\subsection{Social Influence}

Previous studies have empirically proved that social influence positively affects individuals' intention to adopt different kinds of health information technologies and wearable devices [14,23], as well as smart objects $[17,25,36]$. In the context of IoT products and applications adoption and use, social influence processes represent how important the instrumental benefits of using a system are. Venkatesh and Bala [37] synthesized prior research on TAM and developed a theoretical framework, in which social influence is a determinant factor of PEOU and PU.

Accordingly, this study recommends the following hypotheses:

Hypothesis 8 (H8). Social influence positively influences perceived usefulness of IoT products and applications.

Hypothesis 9 (H9). Social influence positively influences perceived ease of use of IoT products and applications. 


\subsection{Cognitive Instrumentals}

Technology adoption is influenced by several factors including cognitive abilities. The technology acceptance model 2 (TAM2) theorizes that (in addition to social influence) people also form PU judgments in part by cognitively comparing what a system is capable of doing with what they need to achieve in their job [3]. They defined the cognitive instrumental process as the mental representations that people use to decide as to whether to adopt a technology or not. The cognitive instrumental factors are [3] job relevance, output quality, and result demonstrability. In conformity with the above discussions, the following hypothesis is recommended:

Hypothesis 10 (H10). Cognitive instrumentals positively influence perceived usefulness of IoT products and applications.

\subsection{Cyber Resilience}

Literature is lagging behind in research in the field of individual resilience towards information systems (IS). Cyber resilience is the "ability to continuously deliver the intended outcome despite adverse cyber events" [38]. People with a high level of cyber resilience do not easily feel negative emotions or revert back to the offline world, such as in a situation where they are challenged or demotivated to use an IoT product or application [24]. Considering the relationship between perceived cost/harm and perceived benefit, it can influence acceptance and use of an IoT product.

Considering the above arguments, the following hypothesis was recommended:

Hypothesis 11 (H11). Cyber resilience is positively associated with facilitated appropriation.

\subsection{User Character}

Literature on information and communication technologies (ICTs) mainly focuses on a market's most innovative consumers, such as early adopters and innovators [39]. A consumer who is facilitated to appropriate better will expect and find a better use of the technology. The degree of facilitation can be influenced by a person's character. Age and user mode were taken from the demographics as measurement variables for user character and its influence on facilitated appropriation.

Rogers' research and theory on the diffusion of innovations $[40,41]$ identified some personality traits that help us organize how people will accept a new innovation. Innovators $(2.5 \%$ of total population), is the first category of individuals to adopt an innovation; early adopters (13.5\%) is the second fastest category of individuals who adopt an innovation; early majority (34\%) are individuals that will adopt an innovation after a varying degree of time. Late majority (34\%) are individuals that will adopt an innovation after the average member of the society and laggards (16\%) are the last to adopt an innovation. In the current study, consumers are categorized into two distinct categories. The first is "Consumers first mode" individuals (50\%), where "Innovators" (2.5\%), "Early adopters" $(13.5 \%)$ and "Early majority" (34\%) are included and the second is "Carry-over effect mode" individuals (50\%), where "Late majority" (34\%) and "Laggards" (16\%) are included.

Based on the above it is hypothesized that:

Hypothesis 12 (H12). Consumers with higher user character mode rate will exhibit higher facilitated appropriation.

The relationships are equivalent to twelve research hypotheses, formulated in Table 1. "AT" stands for attitude, "BI" for behavioral intention, "PU" for perceived usefulness, "PEOU" for perceived ease of use, "FA" for facilitated appropriation, " $\mathrm{T}$ " for trust, "SI" for social influence, "CI" for cognitive instrumentals, "CR" for cyber resilience and " $U C$ " user character. 
Table 1. Research hypotheses.

\begin{tabular}{|c|c|c|}
\hline Hypotheses & Connection & Description \\
\hline $\mathrm{H} 1$ & $\mathrm{AT}^{+} \mathrm{BI}$ & $\begin{array}{l}\text { Attitude toward IoT products and applications usage is positively } \\
\text { associated with consumers' behavioral intention to use them. }\end{array}$ \\
\hline $\mathrm{H} 2$ & $\mathrm{PU}^{+} \mathrm{AT}$ & $\begin{array}{l}\text { Perceived Usefulness is positively associated with consumers' attitude } \\
\text { towards IoT products and applications }\end{array}$ \\
\hline H3 & $\mathrm{PEOU}^{+} \mathrm{AT}$ & $\begin{array}{c}\text { Perceived Ease of Use is positively associated with consumers' attitude } \\
\text { towards IoT products and applications }\end{array}$ \\
\hline $\mathrm{H} 4$ & $\mathrm{FA}^{+} \mathrm{PU}$ & $\begin{array}{c}\text { A consumer's facilitated Appropriation can predict his/her Perceived } \\
\text { Usefulness towards IoT products and applications. }\end{array}$ \\
\hline H5 & $\mathrm{PEOU}^{+} \mathrm{PU}$ & There is a positive relationship between PEOU and PU in the context of IoT. \\
\hline H6 & $\mathrm{T}^{+} \mathrm{PU}$ & $\begin{array}{l}\text { Trust will positively influence perceived usefulness related to IoT products } \\
\text { and applications }\end{array}$ \\
\hline H7 & $\mathrm{T}^{+} \mathrm{PEOU}$ & $\begin{array}{l}\text { Trust will positively influence perceived ease of use related to IoT products } \\
\text { and applications. }\end{array}$ \\
\hline $\mathrm{H} 8$ & $\mathrm{SI}^{+} \mathrm{PU}$ & $\begin{array}{l}\text { Social influence positively influences perceived usefulness of IoT products } \\
\text { and applications }\end{array}$ \\
\hline H9 & $\mathrm{SI}^{+} \mathrm{PEOU}$ & $\begin{array}{l}\text { Social influence positively influences perceived ease of use of IoT products } \\
\text { and applications }\end{array}$ \\
\hline $\mathrm{H} 10$ & $\mathrm{CI}^{+} \mathrm{PU}$ & $\begin{array}{l}\text { Cognitive Instrumentals positively influence perceived usefulness of IoT } \\
\text { products and applications }\end{array}$ \\
\hline H11 & $\mathrm{CR}^{+} \mathrm{FA}$ & Cyber-resilience is positively associated to facilitated appropriation. \\
\hline H12 & $\mathrm{UC}^{+} \mathrm{FA}$ & $\begin{array}{c}\text { Consumers with higher user character mode rate will exhibit higher } \\
\text { facilitated appropriation. }\end{array}$ \\
\hline
\end{tabular}

Figure 1 illustrates the proposed IoTAM. The structural equation IoTAM incorporates dimensions belonging to various fields from the existing technology adoption literature. Endogenous and exogenous variables were adapted from already existing models, while others were originally inserted in our proposed model. Behavioral intention is the outcome, and it was used as it is the key component of TAM [4]. Perceived usefulness/perceived ease of use/attitude are three of the mediators and were adopted as being the core functions of TAM [4]. The dimension of facilitated appropriation, as the last mediator, was adopted from Prayoga and Abraham [27,28]. The behavioral belief (antecedent) of trust was taken from the Decomposed Theory of Planned Behavior (DTPB) [42], the construct of social influence (antecedent) was adopted from UTAUT and TAM2 [3], the construct of cognitive instrumentals (antecedent) was adopted from TAM2, the construct of cyber resilience (antecedent) is an original input in a technology acceptance model and the construct of user character (antecedent) is adapted from the research of Hong in 2016 [15]. In total there are five antecedents, four mediators and the outcome.

In Figure 1, the solid line arrows indicate direct relationships between the analyzed concepts. It is hypothesized that consumers with higher user character and lower cyber resilience will exhibit higher facilitated appropriation. In addition, higher levels of cognitive instrumentals will positively influence perceived usefulness. It is also assumed that higher levels of social influence and trust will either directly or indirectly, through perceived ease of use, positively affect consumers' perception of usefulness. Furthermore, it was hypothesized that facilitated appropriation and perceived ease of use will enhance consumers' perceived usefulness. Finally, it is assumed that positive perceived usefulness and ease of use will create positive consumers' attitude, which will in turn lead to positively enhanced behavioral intentions. Appendix A includes all construct names. 


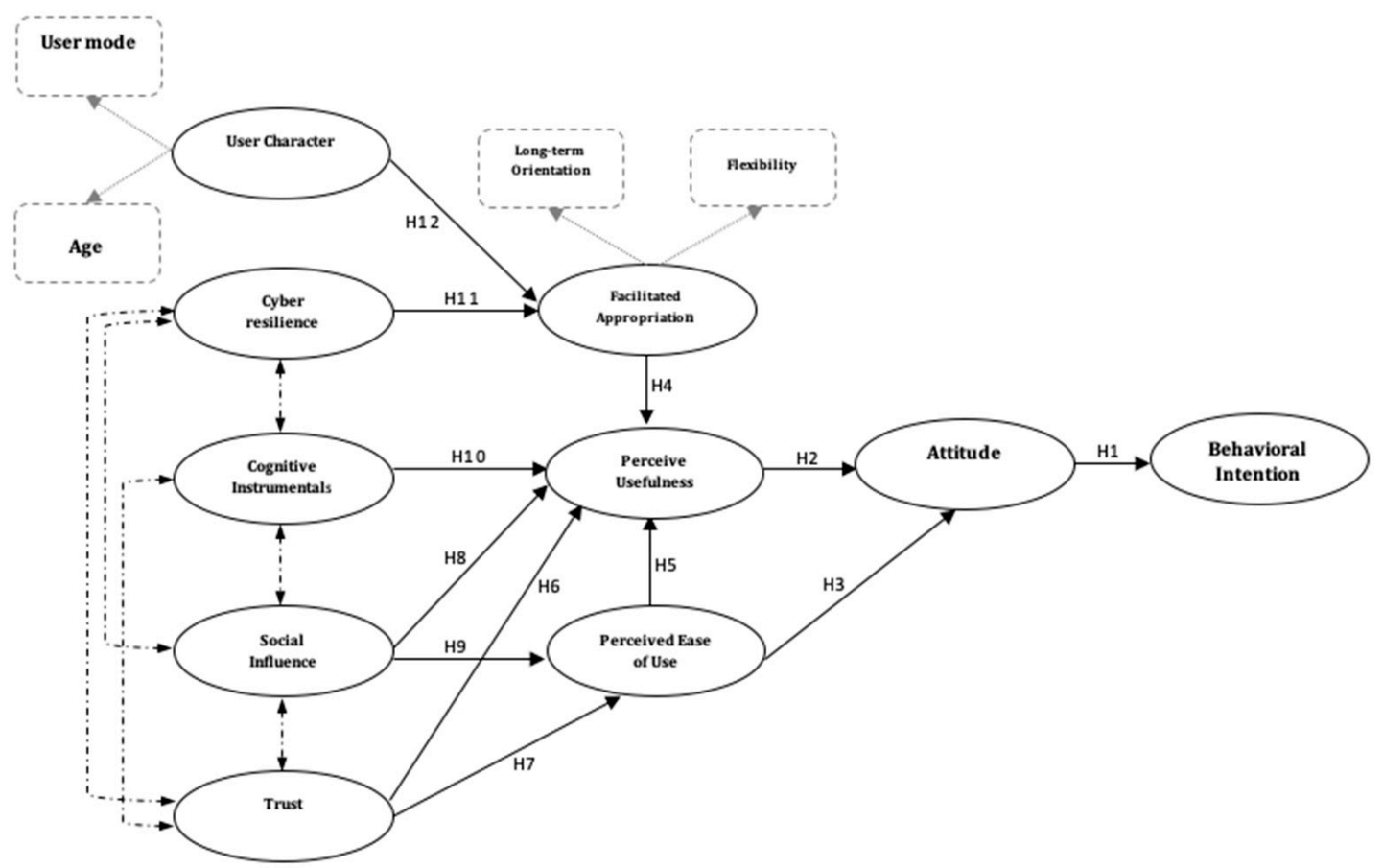

Figure 1. Proposed Internet of Things acceptance model (IoTAM).

\section{Materials and Methods}

\subsection{Sample}

Participants were from Amazon's Mechanical Turk (MTurk), a crowdsourcing service that has become a popular recruiting method in human-computer interaction research [43]. MTurk has emerged as a common and appropriate source of respondents for consumer research [44]. It was used because it is an accepted method of gathering information and has been used by many human-computer and persuasive technology studies $[45,46]$.

Additionally, the study required a large participant sample from a diverse audience and MTurk provides access to a global audience at a relatively low cost and ensures efficient survey distribution and high-quality results [47]. MTurk was considered to be the best option for the current research, which investigates consumers' technology perceptions across a broader population, which is in line with the type of study that it is good at handling [48]. There are many alternatives to MTurk (e.g., CrowdFlower and research-focused participant pools such as Prolific Academic) [49] but MTurk remains the most highly used platform in behavioral and social sciences [50]. The replication-based approach has indicated that results observed on MTurk can generalize other laboratory populations [51]. Research has supported the use of MTurk for use in research that would otherwise not be feasible for in-person data collection or through other alternative crowdsourcing platforms, demonstrating the rewards of these careful designs [49].

The MTurk task description did not directly mention privacy in order to avoid biasing our participant base by attracting people who are more sensitive to privacy concerns, which is similar to the technique in the study by Acquisti and Grossklags [52]. In the main study, a total of 812 responses were included in this analysis, after filtering out incomplete and incorrect responses.

\subsection{Measurement Tool and Statistical Analysis}

To address our research questions, the questionnaire consisted of two parts: demographic profile and construct items. To develop scales for measuring constructs, the measures used, adapted from past research, were modified to suit the context of IoT. Prior to the main study, to test the validity of our study instruments, a pre-test and a pilot study were conducted. The first was on 15 students from International 
Hellenic University (Greece) and the second on 10 participants from MTurk. Pre-test respondents were told to provide comments for the constructs, including the wording of the scales and the length of the survey instrument. Results of both tests show acceptable instrument reliability and validity of the measurements.

The survey questionnaire comprised of both previously validated and created for the context items. Participants were asked to provide their demographic information and respond to 57 statements on the constructs of this study namely: "User character" (created for the context), dichotomic question placing themselves on the first or second user mode category; "Cyber resilience" (created for the context), 10 items; "Social influence" 8 items; "Cognitive instrumentals", 6 items; "Trust", 5 items; "Long-term orientation", 8 items; "Flexibility", 5 items; "Perceived Usefulness", 4 items; "Perceived Ease Of Use", 3 items; "Attitude", 3 items; "Behavioral intention", 5 items. Each statement, except "User character", was measured on a seven-point Likert scale with 1 meaning "strongly disagree" to 7 meaning "strongly agree". The items and their sources are listed in Appendix B and questionnaire is presented in Appendix C.

Descriptive statistics, using IBM SPSS version 19, were made to summarize respondent characteristics and key study variables. Correlations between the key constructs were assessed using Pearson's correlation coefficients. All statistical structural equation modeling (SEM) analyses were conducted with maximum likelihood estimation routines available from IBM SPSS Amos 16. The criteria used to appraise the structural model were model fit indices, as well as the magnitude and direction of path estimates. The standardized path coefficients were assessed to examine the statistical significance and directions of path estimates that exist between the variables in the model. Fit indices used to evaluate the model fit included normed chi square- $\left(\chi^{2} / d f\right)$, goodness of fit (GFI), adjusted goodness of fit index (AGFI) and root mean square error of approximation (RMSEA).

\section{Results}

Table 2 exhibits the demographic characteristics of the 812 survey participants. Trying to fortify the egalitarianism of the sample, we tried to compose the sample of an approximately even number of participants in the context of gender and age. The survey respondents were generally well educated, the majority of them (47.3\%) had a bachelor degree and $22 \%$ declared postgraduate degrees.

User mode was included in demographic characteristics to imprint participants' personal perspective towards the decision to buy/use an IoT product or application. Generally, consumers, known as "early adopters" tend to embrace a new technological product immediately after its introduction to a market. On the other hand, "late adopters" tend to wait and monitor the adoption of new technological products before deciding whether to buy/use or not [15]. According to Rogers [40], consumers are divided to "Innovators", "Early adopters", "Early majority", "Late majority" and "Laggards". As stated above, in this research, "User mode" is divided in "Consumer-first mode", incorporating the first three categories of consumers (50\%), and "Carry-over effect mode" incorporating the last two categories of consumers (50\%). The ratio of "Consumer-first mode" participants to "Carry-over effect mode" participants was about one.

Table 3 shows the descriptive statistics of the latent variables and the reliability coefficients of the tool. Testing the presence of normality is essential. If the data are not normally distributed, the validity and reliability of the results may be affected. Skewness and kurtosis measures were used to check whether data were normally distributed. Skewness value indicates the symmetry of the distribution [53]. A negative skew indicates that the distribution is shifted to the right, whereas positive skew indicates a shift to the left. Kurtosis provides information about the height of the distribution. A positive kurtosis value indicates a peaked distribution, whereas a negative value indicates a flatter distribution. A good measure is obtained by dividing the skewness and kurtosis number by its standard error. The skewness ranged from 0.297 to 1.997 and kurtosis ranged from -0.341 to -1.137 . Following Kline's [53] suggestion that the skew and kurtosis indices should be below 3.0 and 8.0, respectively, there were no severe problems in the data, which were considered 
fairly normal. As shown in Table 3, each measured variable satisfied the assumption of the univariate normality. To analyze the relationship between measured variables, matrices of Pearson product moment correlation coefficients are used to measure the related index between variables.

Table 2. Demographic features of the study sample.

\begin{tabular}{ccc}
\hline Variable & Frequency & $\%$ \\
\hline Gender & & \\
\hline Male & 385 & 47.4 \\
Female & 427 & 52.6 \\
\hline Age & & \\
\hline 20 to 35 years & 452 & 55.7 \\
36 to 51 years & 360 & 44.3 \\
\hline User Mode & & \\
\hline Consumer-first mode & 401 & 49.4 \\
Carry-over effect mode & 411 & 50.6 \\
\hline Education & & \\
\hline High school & 152 & 18.6 \\
Technical College & 98 & 12.1 \\
University & 384 & 47.3 \\
Postgraduate & 178 & 22.0 \\
\hline Occupation & & \\
\hline Employee & 257 & 31.6 \\
Merchant & 146 & 18.0 \\
Housekeeper & 28 & 3.4 \\
Student & 212 & 26.1 \\
Other & 169 & 20.9 \\
\hline
\end{tabular}

Table 3. Descriptive statistics of the latent variables and the reliability coefficients.

\begin{tabular}{|c|c|c|c|c|c|c|c|c|c|}
\hline Variable & Min & $\operatorname{Max}$ & Mean & SD & Kurtosis & & Skewness & & $\begin{array}{c}\text { Cronbach } \\
\text { Alpha }\end{array}$ \\
\hline Cyber-resilience & 10 & 70 & 58.02 & 5.948 & -1.137 & 0.087 & 1.997 & 0.204 & 0.846 \\
\hline Long-term orientation & 8 & 56 & 38.27 & 5.764 & -0.341 & 0.087 & -0.572 & 0.204 & 0.871 \\
\hline Flexibility & 5 & 35 & 23.12 & 4.546 & -0.796 & 0.087 & 0.746 & 0.204 & 0.915 \\
\hline Trust & 5 & 35 & 21.57 & 4.208 & -0.391 & 0.087 & 0.724 & 0.204 & 0.894 \\
\hline Perceived ease of use & 3 & 21 & 17.93 & 3.218 & -0.694 & 0.087 & 0.782 & 0.204 & 0.914 \\
\hline Perceived usefulness & 4 & 28 & 19.81 & 3.957 & -0.504 & 0.087 & 0.297 & 0.204 & 0.831 \\
\hline Attitude & 3 & 21 & 17.82 & 3.168 & -0.911 & 0.087 & 1.146 & 0.204 & 0.927 \\
\hline Behavioral intention & 5 & 35 & 31.42 & 4.347 & -0.964 & 0.087 & 1.108 & 0.204 & 0.931 \\
\hline
\end{tabular}

Samples to be tested are based on the questions of every construct. As Table 4 shows, each IoTAM's Pearson correlation coefficient factors range from 0.006 to 0.829 . 
Table 4. Correlation coefficients between measured variables.

\begin{tabular}{|c|c|c|c|c|c|c|c|c|c|c|c|c|}
\hline & Age & UM & CR & CI & LTO & Fl & TR & SI & PEOU & PU & AT & BI \\
\hline Age & 1 & & & & & & & & & & & \\
\hline UM & $-0.129^{* *}$ & 1 & & & & & & & & & & \\
\hline CR & $0.164^{* *}$ & -0.034 & 1 & & & & & & & & & \\
\hline LTO & 0.028 & $-0.387^{* *}$ & 0.131 ** & $0.146^{* *}$ & 1 & & & & & & & \\
\hline FL & 0.062 & $-0.143^{* *}$ & $0.382^{* *}$ & $0.793^{* *}$ & $0.503^{* *}$ & 1 & & & & & & \\
\hline TR & -0.046 & 0.049 & $0.483^{* *}$ & $0.498^{* *}$ & $0.163^{* *}$ & $0.271^{* *}$ & 1 & & & & & \\
\hline PU & -0.019 & 0.037 & $0.513^{* *}$ & $0.522 * *$ & $0.156^{* *}$ & $0.401^{* *}$ & $0.701^{* *}$ & $0.723^{* *}$ & $0.761^{* *}$ & 1 & & \\
\hline $\mathrm{AT}$ & $0.107^{* *}$ & 0.006 & $0.497^{* *}$ & $0.407^{* *}$ & $0.147^{* *}$ & $0.384^{* *}$ & $0.682^{* *}$ & $0.712^{* *}$ & $0.752^{* *}$ & $0.728^{* *}$ & 1 & \\
\hline BI & $0.162 * *$ & 0.028 & $0.517^{* *}$ & $0.381 * *$ & $0.128^{* *}$ & $0.371^{* *}$ & $0.598^{* *}$ & $0.625^{* *}$ & $0.717^{* *}$ & $0.701 * *$ & $0.829 * *$ & 1 \\
\hline
\end{tabular}

${ }^{*} p<0.05,{ }^{* *} p<0.01$. UM: user mode; CR: cyber-resilience; CI: cognitive instrumentals; LTO: long-term orientation; TR:

trust; SI: social influence; PEOU: perceived ease of use; PU: perceived usefulness; AT: attitude; BI: behavioral intention.

The overall fit of the model was assessed with the following goodness of fit indices representing absolute, comparative and parsimonious aspects of fit: Chi square $-\chi^{2} /$ degree of freedom [53], goodness of fit (GFI): $>0.90$ [53,54], adjusted goodness of fit index (AGFI): $>0.90$ and root mean square error of approximation (RMSEA): $<0.05$ [54]. The overall model fit statistics indicated an overall acceptable fit between data and the conceptual model, proving the adequacy of the model: GFI $=0.93$, AGFI $=0.93$, RMSEA $=0.04, \mathrm{x} 2(127)=407.26, p<0.001$.

Attitude interprets $60.4 \%$, facilitated appropriation $21.6 \%$, PU $50.8 \%$ and PEOU $51.7 \%$ of the variances. In total, the proposed model explains $71.8 \%$ of the behavioral intention variances, since the concerned $\mathrm{R} 2=0.718$. Figure 2 presents the results of the structural model, including path coefficients and variances explained. Table 5 exhibits standardized and unstandardized estimates of the model for each endogenous variable. The model included five exogenous variables: user character, cyber resilience, cognitive instrumental, social influence and trust. The only endogenous outcome in Figure 2 was behavioral intention - the final outcome. The remaining variables, facilitated appropriation, perceived usefulness, perceived ease of use and attitude, were included as endogenous variables that mediate some part of the effect of antecedent variables on subsequent variables. Each of these endogenous variables are explained by other variables in the model (Table 5). Results indicate that PEOU is a stronger predictor of attitude than PU, as well as that PEOU predicts PU stronger than facilitated appropriation (Table 5).

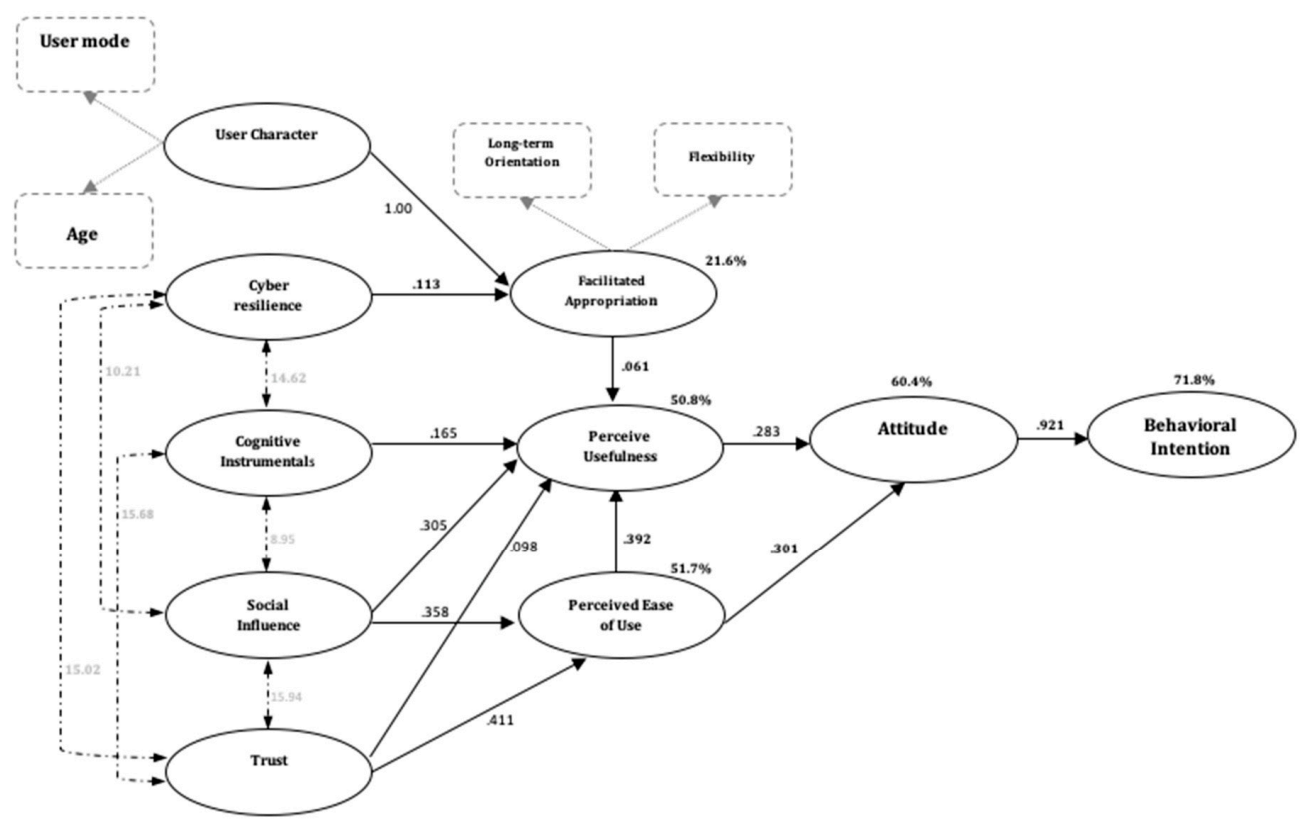

Figure 2. Internet of Things (IoT) acceptance model. 
Table 5. Standardized estimates of IoT acceptance model.

\begin{tabular}{|c|c|c|c|c|c|c|}
\hline Endogenous & Exogenous & SE & Beta & $\mathbf{t}$ & $p$ & SMC \\
\hline \multirow{2}{*}{$\begin{array}{c}\text { Facilitated } \\
\text { Appropriation }\end{array}$} & User character & $\begin{array}{c}1.000 \\
(0.342)\end{array}$ & 0.398 & 2.924 & 0.003 & \multirow{2}{*}{0.196} \\
\hline & Cyber resilience & $\begin{array}{c}0.113 \\
(0.038)\end{array}$ & 0.128 & 2.973 & $<0.001$ & \\
\hline \multirow{2}{*}{ PEOU } & Social influence & $\begin{array}{c}0.358 \\
(0.042)\end{array}$ & 0.349 & 8.523 & $<0.001$ & \multirow{2}{*}{0.648} \\
\hline & Trust & $\begin{array}{c}0.411 \\
(0.021)\end{array}$ & 0.483 & 19.571 & $<0.001$ & \\
\hline \multirow{5}{*}{ PU } & Cognitive instrumentals & $\begin{array}{c}0.165 \\
(0.037)\end{array}$ & 0.161 & 4.459 & $<0.001$ & \multirow{5}{*}{0.661} \\
\hline & Social influence & $\begin{array}{c}0.305 \\
(0.039)\end{array}$ & 0.302 & 7.820 & $<0.001$ & \\
\hline & PEOU & $\begin{array}{c}0.392 \\
(0.039)\end{array}$ & 0.462 & 10.051 & $<0.001$ & \\
\hline & Facilitated Appropriation & $\begin{array}{c}0.061 \\
(0.031)\end{array}$ & 0.058 & 1.967 & 0.09 & \\
\hline & Trust & $\begin{array}{c}0.098 \\
(0.035)\end{array}$ & 0.136 & 2.800 & 0.001 & \\
\hline \multirow{2}{*}{ Attitude } & PU & $\begin{array}{c}0.283 \\
(0.028)\end{array}$ & 0.458 & 10.107 & $<0.001$ & \multirow{2}{*}{0.698} \\
\hline & PEOU & $\begin{array}{c}0.301 \\
(0.019)\end{array}$ & 0.496 & 15.842 & $<0.001$ & \\
\hline Behavioral intention & Attitude & $\begin{array}{c}0.921 \\
(0.025)\end{array}$ & 0.927 & 36.840 & $<0.001$ & 0.812 \\
\hline
\end{tabular}

Table 6 presents standardized effects of direct, indirect, and total effects of exogenous variables on endogenous variables. The direct effect of facilitated appropriation on PU and the indirect effect of user character on attitude are close to being statistically significant. Facilitated appropriation on behavioral intention is at the margin of statistical significance. All other direct, indirect and total effects were statistically significant, at $p<0.05$. Considering both direct and indirect effects of the variables on behavioral intention, the strongest total effect was from attitude followed by PU and PEOU. The path model revealed that there is a significant indirect effect of the variables on attitide and ultimately on behavioral inention.

Table 6. Effects of exogenous variables on endogenous variables in IoT acceptance model.

\begin{tabular}{|c|c|c|c|c|c|c|c|}
\hline Endogenous & Exogenous & $\begin{array}{c}\text { Standardized } \\
\text { Direct Effect }\end{array}$ & $p$ & $\begin{array}{l}\text { Standardized } \\
\text { Indirect Effect }\end{array}$ & $p$ & $\begin{array}{c}\text { Standardized } \\
\text { Total Effect }\end{array}$ & $p$ \\
\hline \multirow[t]{2}{*}{ FA } & UC & 0.398 & 0.01 & - & & 0.398 & 0.01 \\
\hline & CR & 0.128 & 0.007 & - & & 0.128 & 0.007 \\
\hline \multirow[t]{2}{*}{ PEOU } & TR & 0.483 & 0.008 & - & & 0.483 & 0.008 \\
\hline & SI & 0.349 & 0.01 & - & & 0.349 & 0.01 \\
\hline \multirow[t]{7}{*}{$\mathrm{PU}$} & TR & 0.136 & 0.008 & 0.247 & 0.03 & 0.383 & 0.008 \\
\hline & SI & 0.302 & 0.008 & 0.141 & 0.008 & 0.443 & 0.008 \\
\hline & $\mathrm{CI}$ & 0.161 & 0.01 & - & & 0.161 & 0.01 \\
\hline & FA & 0.058 & 0.05 & - & & 0.058 & 0.05 \\
\hline & PEOU & 0.462 & 0.007 & - & & 0.462 & 0.007 \\
\hline & CR & - & & 0.009 & 0.03 & 0.009 & 0.03 \\
\hline & UC & - & & 0.021 & 0.04 & 0.021 & 0.04 \\
\hline
\end{tabular}


Table 6. Cont.

\begin{tabular}{|c|c|c|c|c|c|c|c|}
\hline Endogenous & Exogenous & $\begin{array}{l}\text { Standardized } \\
\text { Direct Effect }\end{array}$ & $p$ & $\begin{array}{l}\text { Standardized } \\
\text { Indirect Effect }\end{array}$ & $p$ & $\begin{array}{l}\text { Standardized } \\
\text { Total Effect }\end{array}$ & $p$ \\
\hline \multirow[t]{8}{*}{ AT } & PEOU & 0.496 & 0.03 & 0.201 & 0.004 & 0.697 & 0.03 \\
\hline & PU & 0.458 & 0.005 & - & & 0.458 & 0.005 \\
\hline & SI & - & & 0.324 & 0.02 & 0.324 & 0.02 \\
\hline & TR & - & & 0.436 & 0.01 & 0.436 & 0.01 \\
\hline & $\mathrm{CI}$ & - & & 0.071 & 0.004 & 0.071 & 0.004 \\
\hline & CR & - & & 0.003 & 0.02 & 0.003 & 0.02 \\
\hline & UC & - & & 0.006 & 0.05 & 0.006 & 0.05 \\
\hline & FA & - & & 0.023 & 0.04 & 0.023 & 0.04 \\
\hline \multirow[t]{9}{*}{ BI } & $\mathrm{AT}$ & 0.927 & 0.01 & - & & 0.927 & 0.01 \\
\hline & SI & - & & 0.349 & 0.02 & 0.349 & 0.02 \\
\hline & TR & - & & 0.362 & 0.01 & 0.362 & 0.01 \\
\hline & CI & - & & 0.072 & 0.005 & 0.072 & 0.005 \\
\hline & CR & - & & 0.005 & 0.03 & 0.005 & 0.03 \\
\hline & $\mathrm{UC}$ & - & & 0.009 & 0.04 & 0.009 & 0.04 \\
\hline & FA & - & & 0.025 & 0.06 & 0.025 & 0.06 \\
\hline & PEOU & - & & 0.592 & 0.01 & 0.592 & 0.01 \\
\hline & PU & - & & 0.407 & 0.004 & 0.407 & 0.004 \\
\hline
\end{tabular}

UM: user mode; CR: cyber-resilience; CI: cognitive instrumentals; LTO: long-term orientation; TR: trust; SI: social influence; PEOU: perceived ease of use; PU: perceived usefulness; AT: attitude; BI: behavioral intention.

\section{Discussion of Findings}

Figure 2 illustrates the outcome effect validation of the model. The overall fitness indices for the IoTAM indicated an acceptable fit. It showed that facilitated appropriation can be explained to the tune of $21.6 \%$ by user character and cyber resilience. It appears that PU can be explained to the tune of $50.8 \%$ by FA, CI, SI, trust and PEOU. PEOU can be explained to the tune of $51.7 \%$ by SI and trust. Attitude can be explained to the tune of $60.4 \%$ by PU and PEOU. BI can be explained to the tune of $71.8 \%$ by attitude. It also apparent that user character explains the strongest FA as the concerned path coefficient $(\beta=1.000)$ is strongest. FA was found to be the mediator in the series of constructs starting from user character, to FA, to PU, to attitude and finally to the outcome BI. This translates to an upswing of behavioral intention towards IoT products and applications. Since personal character influences attitude formation through facilitated appropriation, it is proven that the facilitation degree is affected more by consumers' technology stance than their age.

Implicitly, it is presumed that consumers will have the technological knowledge and skills to deal with this "digital environment". However, without any formal technology prerequisites, individuals are equipped with differing technological skills, stratified by prior experience. Beyond skills, individuals vary in their history with technology, which results in a range of technology identities, influencing their relationship with technology. Since technology expertise is not just a set of technical skills but a bundle of interactions, experiences and understandings of a new technology, knowledge about technology affects an individual's technology stance $[55,56]$ and according to our results, technology stance strongly influences facilitation. Therefore, it is concluded that previous knowledge about technology affects facilitation. Accordingly, Porter and Donthu [57] proved that in the context of internet use particular beliefs about technology adoption rates differently affect consumers representing diverse segments of the population.

Trust explains PEOU stronger than social influence, since the concerned path coefficient $(\beta=0.411)$ is higher. It is observed that trust of consumers, as a focal construct in social psychology, strongly affects PU (trust $\rightarrow$ PEOU), probably because, especially in an online environment, consumers feel free to explore every aspect of the new IoT product or application only if they believe that there will be no privacy breaches and infringements. This trust stimulated "freedom of movements", which probably countersigns a predisposed ease of use. Rooted in Wixom and Todd's integrated framework [58], this model showed how PU and PEOU mediate the effect of trust on individual intention towards IoT technologies. E-commerce research and evidence supports this proposal. Pavlou [35] found that 
Internet consumer trust influenced both PU and PEOU. Additionally, Thatcher et al. [59] found evidence that PEOU either fully or partially mediates the influence of trust in IoT on intention to explore.

Facilitated appropriation was measured by long-term orientation and flexibility. It had a statistically significant indirect effect on attitude through perceived usefulness. This translates to an upswing of behavioral intention towards IoT products and applications. It is proven that PU is significantly influenced by cognitive instrumentals leading to a more positive attitude perception towards IoT products and applications and therefore a higher behavioral intention.

Many of the researchers who have investigated consumers' adoption of IoT technologies have incorporated factors that address the social aspect of adopting new technologies and found significant effects from social influence [60]. In our research, social influence was found to influence PEOU and PU, which in turn influence attitude, which forms behavioral intention. IoT products and applications can be viewed both as fashion products that have aesthetic attributes and could offer consumers the chance to express their characters and values. Our results corroborate with previous research, for example, the significant effect of social influences on behavioral intention to use smartwatches was confirmed by Wu et al. [61], signifying the significant effect of cultural appeal on customers' attitude and intention to use. Trust was also found to significantly influence behavioral intention towards IoT products and applications. Specifically, it can be suggested that higher levels of trust lead to higher levels of PEOU.

Cyber resilience, cognitive instrumentals, social influence and trust, all with different significance rates, prove to be the predicting factors that form the IoTAM. User character and cyber resilience channel a mediating process of facilitated appropriation, where the positive interaction of perceived attitude leads to a positive behavioral intention towards IoT products and applications. The probative value of this result substantiates the fact that when consumers experience an IoT product or application, resilience, as a psychological factor, triggers their problem-solving ability and motivation to deal with emotional stress. To be resilient and adaptive to their new asset, they must find an adaptation solution. An adaptation solution is changing their current way of interacting with the product or applications. As a result, the more resilient consumers are more likely to be able to modify their behavior rapidly to adapt to the change. Concerning the factor of cognitive instrumentals, it is evidenced that potential consumers exhibit a positive PU towards IoT products and applications.

Attitudes are formed when consumers face the various behavioral patterns in their direct social network. Potential consumers of IoT products and applications are found to be more inclined to directly experience, in terms of enjoyment, the effect of social influence. Social influence is confirmed to lead to PEOU directly and to PU either directly or through the mediating process of PEOU, because a consumer who thinks of a system or an application as easy to use will tend to perceive it as being useful as well. The same flow on PEOU and PU is consistent with the last antecedent, trust. The mediating processes lead to positive attitude, which in turn is of paramount importance to the creation of behavioral intentions towards IoT products and applications.

PEOU and PU affect consumers' initial intention to use and are the main determinants of the consumers' attitudes. In our research, it is observed that PEOU $(\beta=0.301)$ explains attitude stronger than PU ( $\beta=0.283)$, a result that contradicts past research results in the wider sphere of new technologies. For example, $\mathrm{PU}$ is found to be more useful than PEOU in predicting consumer attitudes to using mobile commerce [62]. Additionally, according to Yang [63], PU is a more powerful predictor of attitude towards a new technology than PEOU. This may be because in addition to the fact that PU is one of the fundamental antecedents of innovation usage, which is related to the utilitarian value that technology provides to customers [26], it refers to the extent to which target consumers believe that using IT will create significant value for them [64]. Moreover, in the context of a completely new concept, such as IoT, consumers may be more likely to adapt their behavior to the new technology if they perceive it to be easy to use, which refers to PEOU [65] and less to the utilitarian value that it presumably provides. 
PEOU ( $\beta=0.392$ ) is found to exert a significant influence on PU, and both PU and PEOU influence a consumer's behavioral intention to use a new system. This complies with past research [66-69], concluding that PU and PEOU are useful as predictive tools.

This study enables us to draw several conclusions. The overall fitness indices for the IoTAM exhibit an acceptable fit of the model. All path coefficients were statistically significant. It was demonstrated that facilitated appropriation, PU and PEOU significantly influence consumers' attitude and BI towards IoT products and applications. User character, cyber resilience, cognitive instrumentals, social influence and trust exhibited a significantly indirect effect on attitude and BIs, through the three main mediators. The IoTAM is proved to be a practical and serviceable model of investigating how different variables influence BI towards IoT products and applications.

\section{Conclusions}

The goal of this paper was to reveal the factors that define behavioral intention to adopt IoT products and applications among individuals. It was demonstrated that, even though TAM has proven its scientific value and applicability to many different disciplines, its application in the IoT area has not been validated yet. A model that includes both psychological and technical aspects was required to reflect and predict consumer behavioral intention. Remedying this inconsistency, this research provides a foundation for further research through developing and testing IoTAM. The predictive power and applicability of the factors forming IoTAM, all of them with different significance rates and relationship directions, were scientifically substantiated.

Perceived usefulness and perceived ease of use are found to strongly predict and form a positive attitude, which, due to their positive interaction, results in behavioral intention. The first two antecedents of user character and cyber resilience lead to a mediating process of facilitated appropriation towards technology acceptance. When individuals believe they could actually adopt, adapt or incorporate an artefact into working practice, they may seek for an IoT product or application to simplify their lives. Then, they move to assessing their usefulness, which, according to our results, is positive and strongly affects attitude formulation and ultimately behavioral intention. The third antecedent of cognitive instrumentals relates to the mental representation that individuals use to decide whether to adopt a technology or not. Therefore, the positive relationship between cognitive instrumentals and perceived usefulness indicates that individuals exhibit positive cognitions for IoT products and applications, forming a positive perceived usefulness judgment, which eventually leads to a positive attitude and behavioral intention. The fourth antecedent of social influence is found to have the distinctive feature of either having a direct positive influence or an indirect positive influence, through perceived ease of use, on perceived usefulness. This double path is in accordance with the research of Venkatesh and Davis [3], who found that if an individual perceives any technological product/system as easy to use and free of effort, he or she perceives that product/system is more useful. The fifth antecedent of trust shares the same distinctive feature of the double path to perceived usefulness as social influence. It is found that in both paths-indirectly through perceived ease of use and directly to perceived usefulness-trust positively affects perceived usefulness, which in turn strongly predicts attitude formulation, leading to behavioral intention.

\section{Implications for Theory and Practice}

Acceptance of a new technology may be influenced by its merits, but it can also be affected by users' psychological barriers, such as the reluctance to change the status quo [70] and the fear of losing control [71]. Impacts of psychological barriers on consumers' attitudes and behaviors towards IoT products and applications are currently under-researched. To describe behavioral intention towards IoT products and applications, we developed the IoTAM. The integrative psychological-technological viewpoint implies that managers should consider these key factors simultaneously.

The emergence of IoT products and applications has two key consequences. The first is that things will be transformed into "smart things", capable of enhancing existing goods, as well as creating new 
ones. The second is that the large network organization of these smart things will create a wired IoT infrastructure, whose anatomical layers could imitate biological ones. IoT is not just a new technology, but also a completely new way for people to interact with their "brick-and- mortar" environments.

This study has both theoretical and practical implications. The strongest theoretical contribution is that theorizes the factors influencing consumers' behavioral intention towards IoT products and applications from an integrated perspective, including technology perceptions (e.g., perceived usefulness), social context variables (e.g., social influence) and consumers' individual psychological characteristics (e.g., long term orientation). It successfully extends several technology acceptance models, e.g., TAM, in the IoT context, which is extremely different from the context of other information systems. Internet of Things (IoT) helps other information systems to extend provided services while providing flexibility and reachability for things from anywhere to anyone worldwide [72]. What makes the IoT different is that it can function without human-to-human or human-to-computer interaction, as well as utilizing unique identifiers to share information in a network [35]. The IoT system results in the outreach from objects to other objects, and this is the basic characteristic that distinguish IoT systems from traditional information systems.

This IoTAM contributes to current knowledge pertaining to consumer behavior and marketing in two ways. First, theoretical contributions on the factors of consumer behavior towards IoT products and applications is largely neglected in current consumer behavioral and information technology literature. This study tries to fill the literature gap, while calling for further studies, by identifying user mode, social influence, flexibility, long term orientation, cognitive instrumentals and cyber resilience as the additional antecedents of consumer behavioral intention towards IoT products and applications. As a result, the model integrated with technical and psychological features instills an explanation for consumers' behavioral intention, upgrades current knowledge and provides a solid base for examining multirooted models for the acceptance of newly formed technologies.

Accordingly, this research's contribution for practitioners is through its provision of a grassroot template for improving their goods, in order to have a chance of targeting better current customers or attracting new ones. It was substantiated that consumers are not only interested in a useful and easy-to-use IoT product or application, but also expect to fulfil other emotions in order for a positive attitude to be created. Therefore, IoT service providers are advised to offer potential customers products and services that are flexible, challenging, dynamic, beneficial, prestigious, trustworthy and futuristic. With respect to usefulness, IoT practitioners are expected to improve the quality of life and daily performance of consumers through designing IoT products and applications that require the minimum possible effort to accomplish tasks. Furthermore, they need to identify consumers' user modes and stimulate their usage of IoT products and services, so that they can be used as axes, enhancing wider and faster diffusion.

The growth of the internet has led to a different marketing landscape in which consumers actively seek out the opinions of other consumers before making a purchase [73]. Drawn upon the results, marketers should pay attention to the role of social influence on IoT consumer acceptance, given that it is still new. Social influence can play an important role in the diffusion of IoT technologies. Behavioral science suggests that individuals dislike disturbances to social norms and often act in the way that most people do.

Despite the research's results about the variety of sectors that influence customer behavior towards IoT, little is known about the long-run effects of IoT marketing tactics, which is critically important to study in order to understand the strategic marketing implications of IoT technology. Without better knowledge of long-run and competitive outcomes, it will be difficult to address the more basic strategic questions of what markets get served and by whom. If marketers and practitioners want consumers to relate to IoT products and applications, they must find an elaborate way of enticing them to try the products. They need to be visceral and tap into to the most powerful parts of the human psyche.

Integrated marketing communication strategies must be composed, facilitating consumers to accept IoT products and applications by creating interactive marketing tools that will target mostly 
emotion rather than logic. In an interactive world where physical products are no longer the king, these strategies must highlight the profound benefits of IoT products and applications to reduce the psychological barrier. It is obvious that if practitioners want to speed up the pace of the adoption process, they should make the most of the psychology of both creators and consumers of IoT products and applications, rather than rely on only the technical details of what the products are designed to do. In contrast to the conventional wisdom that marketers should mostly emphasize the novelty of new products and congruent with the results of Faraji-Rad et al. [74], this tactic may be specifically problematic among consumer segments that are high in desire for control, which can be identified through aggregate level proxy measures.

By exploring what values trigger consumers to use social IoT products and applications and how these values affect consumers' attitudes toward behavioral intentions, this study helps us understand a beneficial marketing strategy in both theory and practice. It is time to broaden the horizons of consumer behavior because currently used human-centric perspectives diminish the prospect of formulating prominent questions for the future of consumer behavior science.

\section{Limitations and Further Research}

It must be acknowledged that this research model is not a panacea for all possible appliances in the IoT scheme, as the so-called universal attributes of IoT technologies may be influenced by many motivational and technology acceptance theories. Therefore, this research constitutes the foundation for further research in this direction.

Given that this study developed and tested a model explaining the attitude and BI towards IoT products and applications by consumers, there are a number of recommendations for future research. The IoTAM addresses the key concerns of IoT adoption and has relevance for the information technology professionals by offering them a chance to investigate concerned areas, so that they can take act timely and with precision when creating and introducing an IoT product or application. Thus, this model is a straightforward effort to contribute to IoT adoption literature. Future research should consider additional antecedents of the IoTAM and expand it to test its final proposition. Future studies on related topics should therefore extend the findings of this model, by investigating the role of variables using data collected from diverse and international samples, validate them in other contexts and identify additional antecedents of IoT.

Author Contributions: Conceptualization, M.T.; methodology, M.T.; validation M.T. and D.-M.N.; formal analysis M.T.; resources, D.-M.N.; data curation, M.T.; writing-original draft preparation, M.T and D.-M.N.; writing-review and editing, M.T.; visualization, D.-M.N.; supervision, M.T. All authors have read and agreed to the published version of the manuscript.

Funding: This research was funded by the Master in Public Business Administration (MPA), Department of Business Administration, International Hellenic University, as research derived by the project of Nerantzaki Dafni.

Acknowledgments: We wish to acknowledge the funding provided by the Master in Public Business Administration (MPA), Department of Business Administration, International Hellenic University, Serres, Greece.

Conflicts of Interest: The authors declare no conflict of interest. 


\section{Appendix A}

\section{List of Abbreviations}

\begin{tabular}{|c|c|c|c|}
\hline IoT & Internet of Things & TRA & Theory of Reasoned Action \\
\hline IIoT & industrial Internet of Things & TDB & Theory of Planned Behavior \\
\hline TAM & technology acceptance model & $\mathrm{BI}$ & behavioral intention \\
\hline UTAUT & $\begin{array}{l}\text { Unified Theory of Acceptance and Use } \\
\text { of Technology }\end{array}$ & PU & perceived usefulness \\
\hline IS & information systems & PEOU & perceived ease of use \\
\hline DTPB & $\begin{array}{l}\text { Decomposed Theory of Planned } \\
\text { Behavior }\end{array}$ & IDT & Innovation Diffusion Theory \\
\hline ICT & $\begin{array}{l}\text { information and communication } \\
\text { technologies }\end{array}$ & TAM & technology acceptance model \\
\hline IoTAM & $\begin{array}{l}\text { Internet of Things technology } \\
\text { acceptance model }\end{array}$ & FA & facilitated appropriation \\
\hline LTO & long-term orientation & FL & flexibility \\
\hline UC & user character & AT & attitude \\
\hline $\mathrm{CI}$ & cognitive instrumentals & CR & cyber resilience \\
\hline $\mathrm{T}$ & trust & $\mathrm{SI}^{\prime \prime}$ & social influence \\
\hline
\end{tabular}

\section{Appendix B}

Table A1. Constructs Definitions, Number of Measurement Items and Key References.

\begin{tabular}{|c|c|c|c|}
\hline Construct & Definition from Literature & N. of Items & References \\
\hline User mode & $\begin{array}{l}\text { Personality categories towards the acceptance of a } \\
\text { new innovation }\end{array}$ & 2 & $\begin{array}{l}\text { Created for the context } \\
\text { (self-generated), based } \\
\text { on Rogers [40] }\end{array}$ \\
\hline Cyber-resilience & $\begin{array}{l}\text { The ability to continuously deliver the intended } \\
\text { outcome despite adverse cyber events }\end{array}$ & 10 & $\begin{array}{l}\text { Created for the context: } \\
\text { [75-77] }\end{array}$ \\
\hline $\begin{array}{c}\text { Cognitive } \\
\text { instrumentals }\end{array}$ & $\begin{array}{l}\text { The mental representations that people use to make a } \\
\text { decision as to whether to adopt a technology or not. }\end{array}$ & 6 & {$[3,78]$} \\
\hline Social influence & $\begin{array}{l}\text { A psychological concept that acts as the balancing act } \\
\text { between self-understand the interests of others }\end{array}$ & 8 & {$[3,78]$} \\
\hline Trust & $\begin{array}{l}\text { The individual's belief in three main aspects, which } \\
\text { are ability, integrity, and benevolence, which, in turn, } \\
\text { makes customers feel the targeted technology is } \\
\text { more dependable and trustworthy to use. }\end{array}$ & 5 & {$[79,80]$} \\
\hline $\begin{array}{l}\text { Long-term } \\
\text { orientation }\end{array}$ & $\begin{array}{l}\text { Long term orientation can be seen as valuing } \\
\text { prospect of the future, and deeming actions } \\
\text { unimportant for the short-term achievement. }\end{array}$ & 8 & {$[24,28,32,81]$} \\
\hline Flexibility & $\begin{array}{c}\text { The degree to which a user of a particular IoT system } \\
\text { believes that he could efficiently use it in many } \\
\text { diverse environments or for achieving different } \\
\text { objectives beyond those initially specified in the } \\
\text { requirements. }\end{array}$ & 5 & $\begin{array}{l}\text { Self-generated-Scale } \\
\text { developed using the } \\
\text { definition of Economidis } \\
\text { [82] }\end{array}$ \\
\hline $\begin{array}{l}\text { Perceived } \\
\text { usefulness }\end{array}$ & $\begin{array}{l}\text { The degree to which a user believes that using a } \\
\text { particular IoT system he would achieve results and } \\
\text { outcomes that he considers useful }\end{array}$ & 4 & {$[4,31]$} \\
\hline
\end{tabular}


Table A1. Cont.

\begin{tabular}{cccc}
\hline Construct & \multicolumn{1}{c}{ Definition from Literature } & N. of Items & References \\
\hline $\begin{array}{c}\text { Perceived ease of } \\
\text { use }\end{array}$ & $\begin{array}{c}\text { The degree to which a user believes that using a } \\
\text { particular IoT system would be easy and without } \\
\text { much effort to carry it, to install it, to initiate it, to } \\
\text { understand its usage, to learn its usage, to remember } \\
\text { its usage, as well as to actually access, use, control, } \\
\text { maintain, pay and terminate it }\end{array}$ & 3 & [4,31] \\
\hline Attitude & $\begin{array}{c}\text { The degree to which users have positive feelings } \\
\text { about using IoT services. }\end{array}$ & 3 & [83] \\
\hline $\begin{array}{c}\text { Behavioral } \\
\text { intention }\end{array}$ & $\begin{array}{c}\text { The strength of an individual's desire to perform a } \\
\text { behavior, which is intended to capture } \\
\text { "acceptance-like" processes }\end{array}$ & 5 & [31,84] \\
\hline
\end{tabular}

\section{Appendix C}

\section{Appendix C.1. Operationalization of the Constructs}

\section{Appendix C.1.1. Cyber-Resilience}

CR1 I am able to adapt to change.

CR2 I can deal with whatever comes.

CR3 I am in control of my life.

CR4 I can cope with pressure and stress. It strengthens me.

CR5 I prefer to take the lead in problem solving.

CR6 I can achieve goals despite obstacles.

CR7 I have pride in my achievements.

CR8 I am not easily discouraged by failure.

CR9 I think of myself as a strong person.

CR10 I like challenges.

\section{Appendix C.1.2. Cognitive Instrumentals}

CR11 IoT products and applications are very much applicable to my tasks.

CR12 With IoT products and applications, meeting information needs is much more flexible and dynamic.

CR13 IoT products and applications provide multi-access and searching capability.

CR14 The output of IoT products and applications are error-free.

CR15 I do not have difficulty attributing gains to the use of IoT products and applications.

CR16 The usefulness and benefits of IoT products and applications are readily and easily discernible.

\section{Appendix C.1.3. Social Influence}

SI1 People who are important to me would recommend using IoT products and applications.

SI2 People who are important to me would find using IoT products and applications beneficial.

SI3 People who influence my behavior think that I should use IoT products and applications.

SI4 People in my environment who use IoT products and applications have a high profile.

SI5 Using IoT products and applications is considered a status symbol.

SI6 People in my environment who use IoT products and applications have more prestige than those who do not.

SI7 I have seen people who are important to me using IoT products and applications.

SI8 Previous knowledge informs my present appreciation of IoT products and applications in the connected world environment. 


\section{Appendix C.1.4. Trust}

TR1 IoT products and applications are trustworthy.

TR2 IoT products and applications providers keep my best interests in mind.

TR3 IoT products and applications provide reliable information.

TR4 IoT products and applications providers keep promises and commitments.

TR5 I feel assured that IoT products and applications providers protect me from problems I may encounter.

TR6 IoT products and applications are trustworthy.

\section{Appendix C.1.5. Long-Term Orientation}

LTO1 Respect for tradition is important to me.

LTO2 I plan for the long term.

LTO3 Family heritage is important to me.

LTO4 I value a strong link to my past.

LTO5 I work hard for success in the future.

LTO6 I do not mind giving up today's fun for success in the future.

LTO7 Traditional values are important to me.

LTO8 Persistence is important to me.

Appendix C.1.6. Flexibility

FL1 I believe in IoT products and applications versatility.

FL2 I believe in IoT products and applications portability.

FL3 I believe in IoT products and applications transferability.

FL4 I believe in IoT products and applications reusability.

FL5 I believe in IoT products and applications modifiability.

\section{Appendix C.1.7. Perceived Usefulness}

PU1 I think that IoT products and applications will improve my performance of daily activities and tasks.

PU2 I think that IoT products and applications will make it easier for me to do my daily activities and tasks.

PU3 I think that IoT products and applications will reduce the effort required in accomplishing my daily activities and tasks.

PU4 I think that IoT products and applications will improve my quality of life.

PU5 I think that IoT products and applications will improve my performance of daily activities and tasks.

\section{Appendix C.1.8. Perceived Ease of Use}

PEOU1 Learning to use IoT products and applications is clear and easy for me.

PEOU2 Using IoT products and applications does not require a lot of mental/physical effort.

PEOU3 I think using IoT products and applications is easy and understandable.

\section{Appendix C.1.9. Attitude}

AT1 I like using IoT products and applications.

AT2 I feel good about using IoT products and applications.

AT3 Overall, my attitude towards using IoT products and applications is favorable. 


\section{Appendix C.1.10. Behavioral Intention}

BI1 Given the chance, I intend to use IoT products and applications.

BI2 I am willing to use IoT products and applications in the near future.

BI3 I will frequently use IoT products and applications.

BI4 I will recommend IoT products and applications to others.

BI5 I will continue using IoT products and applications in the future.

\section{References}

1. Ashton, K. That 'internet of things' thing. Rfid J. 2009, 22, 97-114.

2. Peoples, C.; Parr, G.; McClean, S.; Scotney, B.; Morrow, P. Performance evaluation of green data centre management supporting sustainable growth of the internet of things. Simul. Model. Pract. Theory 2013, 34, 221-242. [CrossRef]

3. McLellan, C. Cyber Security in 2015: What to Expect; 2015; Available online: https://www.zdnet.com/article/ cybersecurity-in-2015-what-to-expect/ (accessed on 3 November 2020).

4. Davis, F.D. Perceived usefulness, perceived ease of use, and user acceptance of information technology. Mis Q. 1989, 13, 319-340. [CrossRef]

5. Bagozzi, R.P. The legacy of the technology acceptance model and a proposal for a paradigm shift. J. Assoc. Inf. Syst. 2007, 8, 244-254. [CrossRef]

6. Benbasat, I.; Barki, H. Quo vadis, TAM? J. Assoc. Inf. Syst. 2007, 8, 211-218. [CrossRef]

7. Moon, J.W.; Kim, Y.G. Extending the TAM for a World-Wide-Web context. Inf. Manag. 2001, 38, 217-230. [CrossRef]

8. Macik, R. The Adoption of the Internet of Things by Young Consumers-an Empirical Investigation. Econ. Environ. Stud. 2017, 17, 363-388. [CrossRef]

9. Shang, W.; Yu, Y.; Droms, R.; Zhang, L. Challenges in IoT networking via TCP/IP architecture. In Technical Report NDN-0038; Available online: https://named-data.net/wp-content/uploads/2016/02/ndn-0038-1challenges-iot.pdf (accessed on 29 October 2020).

10. Hancke, G.P.; Markantonakis, K.; Mayes, K.E. Security challenges for user-oriented RFID applications within the "Internet of things". J. Int. Technol. 2010, 11, 307-313.

11. Medaglia, C.M.; Serbanati, A. An overview of privacy and security issues in the internet of things. In Internet Things; Springer: Berlin/Heidelberg, Germany, 2010; pp. 389-395.

12. Mendez Mena, D.; Papapanagiotou, I.; Yang, B. Internet of things: Survey on security. Inf. Secur. J. A Glob. Perspect. 2018, 27, 162-182. [CrossRef]

13. Uckelmann, D.; Harrison, M.; Michahelles, F. An architectural approach towards the future internet of things. In Archit. Internet Things; Springer: Berlin/Heidelberg, Germany, 2011; pp. 1-24.

14. Guinard, D.; Trifa, V.; Mattern, F.; Wilde, E. From the internet of things to the web of things: Resource-oriented architecture and best practices. In Architecting the Internet of Things; Springer: Berlin/Heidelberg, Germany, 2011; pp. 97-129.

15. Hong, H.G. Measurement Framework for the Acceptance of Internet of Things Product. Indian J. Sci. Technol. 2016, 9, 46

16. Atzori, L.; Iera, A.; Morabito, G. Siot: Giving a social structure to the internet of things. IEEE Commun. Lett. 2011, 15, 1193-1195. [CrossRef]

17. Turhan, G. An assessment towards the acceptance of wearable technology to consumers in Turkey: The application to smart bra and t-shirt products. J. Text. Inst. 2013, 104, 375-395. [CrossRef]

18. Istepanian, R.S.; Sungoor, A.; Faisal, A.; Philip, N. Internet of M-Health Things'm-IOT'. Available online: https://digital-library.theiet.org/content/conferences/10.1049/ic.2011.0036 (accessed on 29 October 2020).

19. Gao, Y.; Li, H.; Luo, Y. An empirical study of wearable technology acceptance in healthcare. Ind. Manag. Data Syst. 2015, 115, 1704-1723. [CrossRef]

20. Schlick, J.; Ferber, S.; Hupp, J. IoT applications-value creation for industry. In Aalborg; River Publisher: Gistrup, Denmark, 2013.

21. Li, X.J.; Wang, D. Architecture and existing applications for internet of things. Appl. Mech. Mater. 2013, 347, 3317-3321. [CrossRef] 
22. Evanschitzky, H.; Iyer, G.R.; Pillai, K.G.; Kenning, P.; Schütte, R. Consumer trial, continuous use, and economic benefits of a retail service innovation: The case of the personal shopping assistant. J. Prod. Innov. Manag. 2015, 32, 459-475. [CrossRef]

23. Tsai, M.-C.; Lee, W.; Wu, H.-C. Determinants of RFID adoption intention: Evidence from Taiwanese retail chains. Inf. Manag. 2010, 47, 255-261. [CrossRef]

24. Prayoga, T.; Abraham, J. Technopsychology of IoT Optimization in the Business World. In The Internet of Things in the Modern Business Environment; IGI Global: Hershey, PA, USA, 2017; pp. 50-75. Available online: https://www.igi-global.com/chapter/technopsychology-of-iot-optimization-inthe-business-world/234934 (accessed on 29 October 2020).

25. Rauschnabel, P.A.; Brem, A.; Vens, B.S. Who will buy smart glasses? Empirical results of two pre-market-entry studies on the role of personality in individual awareness and intended adoption of Google Glass wearables. Comput. Hum. Behav. 2015, 49, 635-647. [CrossRef]

26. Revels, J.; Tojib, D.; Tsarenko, Y. Understanding consumer intention to use mobile services. Australas Mark. J. 2010, 18, 74-80. [CrossRef]

27. Prayoga, T.; Abraham, J. Behavioral Intention to Use IoT Health Device: The Role of Perceived Usefulness, Facilitated Appropriation, Big Five Personality Traits, and Cultural Value Orientations. Int. J. Electr. Comput. Eng. 2016, 6, 1751-1765.

28. Prayoga, T.; Abraham, J. Social-Psychological-Health Predictors of Fondness of Arkenstone among Indonesians. Abnorm. Behav. Psychol. 2016, 2, 1000116. [CrossRef]

29. Gursoy, D.; Spangenberg, E.R.; Rutherford, D.G. The hedonic and utilitarian dimensions of attendees' attitudes toward festivals. J. Hosp. Tour. Res. 2006, 30, 279-294. [CrossRef]

30. Karahoca, A.; Karahoca, D.; Aksöz, M. Examining intention to adopt to internet of things in healthcare technology products. Kybernetes 2018, 47, 742-770. [CrossRef]

31. Gao, L.; Bai, X. A unified perspective on the factors influencing consumer acceptance of internet of things technology. Asia Pac. J. Mark. Logist. 2014, 26, 211-231. [CrossRef]

32. Bearden, W.O.; Money, R.B.; Nevins, J.L. A measure of long-term orientation: Development and validation. J. Acad. Mark. Sci. 2006, 34, 456-467. [CrossRef]

33. Venkatesh, V.; Davis, F.D. A theoretical extension of the technology acceptance model: Four longitudinal field studies. Manag. Sci. 2000, 46, 186-204. [CrossRef]

34. Ha, S.; Stoel, L. Consumer e-shopping acceptance: Antecedents in a technology acceptance model. J. Bus. Res. 2009, 62, 565-571. [CrossRef]

35. Pavlou, P.A. Consumer acceptance of electronic commerce: Integrating trust and risk with the technology acceptance model. Int. J. Electron. Commer. 2003, 7, 101-134.

36. Kalantari, M. Consumers' adoption of wearable technologies: Literature review, synthesis, and future research agenda. Int. J. Technol. Mark. 2017, 12, 274-307. [CrossRef]

37. Venkatesh, V.; Bala, H. Technology acceptance model 3 and a research agenda on interventions. Decis. Sci. 2008, 39, 273-315. [CrossRef]

38. Björck, F.; Henkel, M.; Stirna, J.; Zdravkovic, J. Cyber resilience-fundamentals for a definition. In New Contributions in Information Systems and Technologies; Springer: Berlin/Heidelberg, Germany, 2015; pp. 311-316.

39. Verdegem, P.; De Marez, L. Rethinking determinants of ICT acceptance: Towards an integrated and comprehensive overview. Technovation 2011, 31, 411-423. [CrossRef]

40. Rogers, E.M. Diffusion of Innovation, 4th ed.; The Free: New York, NY, USA, 1995.

41. Rogers, E.M. Diffusion of Innovations; Simon and Schuster: New York, NY, USA, 2010.

42. Taylor, S.; Todd, P. Decomposition and crossover effects in the theory of planned behavior: A study of consumer adoption intentions. Int. J. Res. Mark. 1995, 12, 137-155. [CrossRef]

43. Kittur, A.; Chi, E.H.; Suh, B. Crowdsourcing user studies with Mechanical Turk. In Proceedings of the SIGCHI Conference on Human Factors in Computing Systems, Montreal, QC, Canada, 25-30 April 2018; ACM: New York, NY, USA, 2018; pp. 453-456.

44. Paolacci, G.; Chandler, J.; Ipeirotis, P.G. Running experiments on Amazon mechanical Turk. Judgm. Decis. Mak. 2010, 5, 411-419.

45. Hirsh, J.B.; Kang, S.K.; Bodenhausen, G.V. Personalized persuasion: Tailoring persuasive appeals to recipients' personality traits. Psychol. Sci. 2012, 23, 578-581. [CrossRef] 
46. Jia, Y.; Xu, B.; Karanam, Y.; Voida, S. Personality-targeted gamification: A survey study on personality traits and motivational affordances. In Proceedings of the 2016 CHI Conference on Human Factors in Computing Systems, San Jose, CA, USA, 7-12 May 2016; ACM: New York, NY, USA; pp. 2001-2013.

47. Buhrmester, M.; Kwang, T.; Gosling, S.D. Amazon's Mechanical Turk: A new source of inexpensive, yet high-quality, data? Perspect. Psychol. Sci. 2011, 6, 3-5. [CrossRef]

48. Bentley, F.R.; Daskalova, N.; White, B. Comparing the reliability of Amazon Mechanical Turk and Survey Monkey to traditional market research surveys. In Proceedings of the $2017 \mathrm{CHI}$ Conference Extended Abstracts on Human Factors in Computing Systems, Denver, CO, USA, 6-11 May 2017; ACM: New York, NY, USA, 2017; pp. 1092-1099.

49. Palan, S.; Schitter, C. Prolific. ac-A subject pool for online experiments. J. Behav. Exp. Financ. 2018, 17, $22-27$. [CrossRef]

50. Mellis, A.M.; Bickel, W.K. Mechanical Turk data collection in addiction research: Utility, concerns and best practices. Addiction 2020, 115, 1960-1968. [CrossRef]

51. Coppock, A.; McClellan, O.A. Validating the demographic, political, psychological, and experimental results obtained from a new source of online survey respondents. Res. Politics 2019, 6, 1. [CrossRef]

52. Acquisti, A.; Grossklags, J. Privacy and rationality in individual decision making. IEEE Secur. Priv. 2005, 3, 26-33. [CrossRef]

53. Kline, R.B. Principles and Practices of Structural Equation Modeling; Guilford Press: New York, NY, USA, 2005.

54. McDonald, R.P.; Ho, M.H.R. Principles and practice in reporting structural equation analyses. Psychol. Methods 2002, 7, 64. [CrossRef]

55. Kim, S.B.; Sun, K.A.; Kim, D.Y. The influence of consumer value-based factors on attitude-behavioral intention in social commerce: The differences between high-and low-technology experience groups. J. Travel Tour. Mark. 2013, 30, 108-125. [CrossRef]

56. Goode, J. Mind the gap: The digital dimension of college access. J. High. Educ. 2010, 81, 583-618. [CrossRef]

57. Porter, C.E.; Donthu, N. Using the technology acceptance model to explain how attitudes determine Internet usage: The role of perceived access barriers and demographics. J. Bus. Res. 2006, 59, 999-1007. [CrossRef]

58. Wixom, B.H.; Todd, P.A. A theoretical integration of user satisfaction and technology acceptance. Inf. Syst. Res. 2005, 16, 85-102. [CrossRef]

59. Thatcher, J.B.; McKnight, D.H.; Baker, E.W.; Arsal, R.E.; Roberts, N.H. The role of trust in postadoption IT exploration: An empirical examination of knowledge management systems. IEEE Trans. Eng. Manag. 2011, 58, 56-70. [CrossRef]

60. Yang, H.; Yu, J.; Zo, H.; Choi, M. User acceptance of wearable devices: An extended perspective of perceived value. Telemat. Inform. 2016, 33, 256-269. [CrossRef]

61. Wu, L.H.; Wu, L.C.; Chang, S.C. Exploring consumers' intention to accept smartwatch. Comput. Hum. Behav. 2016, 64, 383-392. [CrossRef]

62. Amin, M.; Rezaei, S.; Abolghasemi, M. User satisfaction with mobile websites: The impact of perceived usefulness (PU), perceived ease of use (PEOU) and trust. Nankai Bus. Rev. Int. 2014, 5, 258-274. [CrossRef]

63. Yang, K.C.C. Exploring factors affecting the adoption of mobile commerce in Singapore. Telemat. Inform. 2005, 22, 257-277. [CrossRef]

64. Rouibah, K.; Abbas, H.; Rouibah, S. Factors affecting camera mobile phone adoption before e-shopping in the Arab world. Technol. Soc. 2011, 33, 271-283. [CrossRef]

65. Morosan, C. Theoretical and empirical considerations of guests' perceptions of biometric systems in hotels. J. Hosp. Tour. Res. 2012, 36, 52-84. [CrossRef]

66. Fliegel Frederick, C.; Kivlin Joseph, E. Attributes of innovations as factors in diffusion. Am. J. Sociol. 1966, 72, 235-248. [CrossRef]

67. Ostlund Lyman, E. Perceived innovation attributes as predictors of innovativeness. J. Consum. Res. 1974, 1, 23-29. [CrossRef]

68. Szajna, B. Empirical evaluation of the revised technology acceptance model. Manag. Sci. 1996, 42, 85-92. [CrossRef]

69. Tornatzky, L.G.; Klein, K.J. Innovation characteristics and innovation adoption-implementation: A meta-analysis of findings. IEEE Trans. Eng. Manag. 1982, 1, 28-45. [CrossRef]

70. Heidenreich, S.; Kraemer, T.; Handrich, M. Satisfied and unwilling: Exploring cognitive and situational resistance to innovations. J. Bus. Res. 2016, 69, 2440-2447. [CrossRef] 
71. Laukkanen, $\mathrm{T}$. Consumer adoption versus rejection decisions in seemingly similar service innovations: The case of the Internet and mobile banking. J. Bus. Res. 2016, 69, 2432-2439. [CrossRef]

72. Abuarqoub, A.; Abusaimeh, H.; Hammoudeh, M.; Uliyan, D.; Abu-Hashem, M.A.; Murad, S.; Al-Fayez, F. A survey on internet of things enabled smart campus applications. In Proceedings of the International Conference on Future Networks and Distributed Systems, Cambridge, UK, 19-20 July 2017; pp. 1-7.

73. Kwon, M.; Saluja, G.; Adaval, R. Who said what: The effects of cultural mindsets on perceptions of endorser-message relatedness. J. Consum. Psychol. 2015, 25, 389-403. [CrossRef]

74. Faraji-Rad, A.; Melumad, S.; Johar, G.V. Consumer desire for control as a barrier to new product adoption. J. Consum. Psychol. 2017, 27, 347-354. [CrossRef]

75. Campbell-Sills, L.; Stein, M.B. Psychometric analysis and refinement of the Connor-Davidson resilience scale (CD-RISC): Validation of a 10-item measure of resilience. J. Trauma. Stress Off. Publ. Int. Soc. Trauma. Stress Stud. 2007, 20, 1019-1028. [CrossRef]

76. Connor, K.M.; Davidson, J.R. Development of a new resilience scale: The Connor-Davidson resilience scale (CD-RISC). Depress. Anxiety 2003, 18, 76-82. [CrossRef]

77. Hua, J.; Chen, Y.; Luo, X.R. Are we ready for cyberterrorist attacks?-Examining the role of individual resilience. Inf. Manag. 2018, 55, 928-938. [CrossRef]

78. Izuagbe, R.; Popoola, S.O. Social influence and cognitive instrumental factors as facilitators of perceived usefulness of electronic resources among library personnel in private universities in South-west, Nigeria. Libr. Rev. 2017, 66, 679-694. [CrossRef]

79. Alalwan, A.A.; Baabdullah, A.M.; Rana, N.P.; Tamilmani, K.; Dwivedi, Y.K. Examining adoption of mobile internet in Saudi Arabia: Extending TAM with perceived enjoyment, innovativeness and trust. Technol. Soc. 2018, 55, 100-110. [CrossRef]

80. Gefen, D.; Karahanna, E.; Straub, D.W. Trust and TAM in online shopping: An integrated model. Mis $Q$. 2003, 27, 51-90. [CrossRef]

81. Sharma, P. Measuring personal cultural orientations: Scale development and validation. J. Acad. Mark. Sci. 2010, 38, 787-806. [CrossRef]

82. Economides, A.A. User Perceptions of Internet of Things (IoT) Systems. In Proceedings of the International Conference on E-Business and Telecommunications, Lisbon, Portugal, 26-28 July 2016; Springer: Berlin/Heidelberg, Germany, 2016; pp. 3-20.

83. Hsu, C.L.; Lin, J.C.C. An empirical examination of consumer adoption of Internet of Things services: Network externalities and concern for information privacy perspectives. Comput. Hum. Behav. 2016, 62, 516-527. [CrossRef]

84. Venkatesh, V. Determinants of perceived ease of use: Integrating control, intrinsic motivation, and emotion into the technology acceptance model. Inf. Syst. Res. 2000, 11, 342-365. [CrossRef]

Publisher's Note: MDPI stays neutral with regard to jurisdictional claims in published maps and institutional affiliations.

(C) 2020 by the authors. Licensee MDPI, Basel, Switzerland. This article is an open access article distributed under the terms and conditions of the Creative Commons Attribution (CC BY) license (http://creativecommons.org/licenses/by/4.0/). 